\title{
Dietary Lippia citriodora extract in rabbit feeding: effects on quality of carcass and meat
}

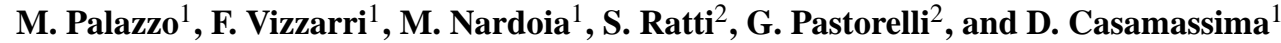 \\ ${ }^{1}$ Department of Agriculture, Environmental and Food Sciences, University of Molise, Campobasso, Italy \\ ${ }^{2}$ Department of Health, Animal Science and Food Safety, University of Milano, Milano, Italy \\ Correspondence to: F. Vizzarri (francesco.vizzarri@unimol.it)
}

Received: 7 July 2015 - Revised: 2 September 2015 - Accepted: 29 September 2015 - Published: 5 October 2015

\begin{abstract}
Due to consumer demand, in recent years considerable attention has been focused on the use of natural compounds in animal feed. The aim of this study was to evaluate the effect of dietary natural extract from Lippia citriodora (commonly named "limoncina"), titrated in verbascoside, on quality, measured as oxidative stability, fatty acid composition, alpha-tocopherol and retinol content and sensory traits of rabbit meat. Forty-five New Zealand white rabbits were randomly assigned to three age- and body-weight-balanced feeding groups of 15 animals each in which a conventional pelleted diet (CON) was supplemented with $1 \mathrm{or}^{2} \mathrm{~kg} \mathrm{t}^{-1}$ (low naturalextract (LNE) and high natural-extract (HNE) groups, respectively) of Lippia citriodora extract for 55 days. No influence on carcass characteristics and the chemical composition of meat was observed. A trend for a positive effect on alpha-tocopherol tissue content $(P=0.07)$ and on thiobarbituric reactive substance (TBARS) values was observed $(P=0.063)$ in Longissimus Lumborum muscle from the HNE group.

The fatty acid profile of the meat was affected by dietary treatment with a significant decrease $(P=0.001)$ in saturated fatty acids and an increase $(P=0.01)$ in polyunsaturated fatty acids in both treated groups compared to the CON group. The supplementation with natural extract at the highest dosage improved the tenderness and juiciness of meat, highlighting a better consistency than CON and LNE groups. In conclusion, this study shows that the natural extract used has the potential to improve rabbit meat in order to produce functional food, without altering the chemical and physical characteristics of meat.
\end{abstract}

\section{Introduction}

Meat and meat products are essential components of the diet in developed countries, and a growing consumption of meat products is foreseen (Olmedilla-Alonso et al., 2006).

Rabbit meat is commonly consumed in many European countries and its production plays an important role in national economies; it is a lean meat rich in proteins of high biological value (Dalle Zotte, 2014), with highly unsaturated lipids, low cholesterol content (Lukefahr et al., 1989), and noticeable quantities of linolenic fatty acid (C18:3n3). Also, it displays a low sodium content and a high phosphorus content and can be a good source of B vitamins (Hernández and Gondret, 2006). Therefore, rabbit meat is characterized by a high digestibility and may be fortified with bioactive compounds to obtain a "functional" product (Dalle Zotte and Szendro, 2011). Lipid oxidation is a major cause of chem- ical spoilage in the food system. The shelf life of meat and meat products can be extended by the presence of natural antioxidants coming from different sources such as plant extracts. In response to recent claims that synthetic antioxidants have the potential to cause toxicological effects and consumers' increased interest in purchasing natural products, the meat industry has been seeking sources of natural antioxidants (Karre et al., 2013). Natural antioxidants have been widely reported to have potent anti-inflammatory and antimicrobic properties related especially to their phenolic content (Pereira et al., 2009). Besides phenolic compounds, verbascoside shows the highest scavenger activity (Wang et al., 1996) and has high antioxidant power in comparison with other phenolic compounds (Aleo et al., 2005). Phenylpropanoids, particularly verbascoside, are the most abundant compounds in Verbenaceae extracts (Pascual et al., 2001). 
Phenylpropanoid glycosides are powerful antioxidants that cause direct scavenging of reactive oxygen and nitrogen species or act as chain-breaking peroxyl radical scavengers (Afanasev, 2005).

Antioxidant supplements in animal diets present the advantage that living animals may efficiently distribute the compounds throughout the tissues, and the resulting enriched animal production ensures tolerable amounts for humans (Bou et al., 2009; Laudadio et al., 2015).

Previous studies have found that a long-term dietary supplementation with a natural extract leads to an antioxidant effect in pork, enhancing its oxidative status, vitamin E content and sensory attributes without affecting other meat quality parameters (Rossi et al., 2013). Dietary verbascoside supplementation improved the average daily gain and milk intake of naturally fed lambs (Casamassima et al., 2013); in addition Vizzarri et al. (2014) found that dietary supplementation of Lippia citriodora extract in hares decreased saturated fatty acids content, cholesterol and thiobarbituric reactive substances (TBARSs) and increased the fat-soluble vitamins (A and $\mathrm{E})$ in meat.

On this basis, the aim of the present study is to evaluate the effect on meat quality in rabbits of dietary supplementation with a natural extract of Lippia citriodora, titrated in verbascoside. The effect is assessed in terms of oxidative stability, fatty acid composition, alpha-tocopherol and retinol content and sensory analysis.

\section{Materials and methods}

\subsection{Animals and experimental design}

The trial was conducted in the Animal Production Research Centre (Nitra, Slovak Republic) experimental rabbitry on 45 weaned and clinically healthy New Zealand white rabbits (in accordance with European Community guidelines no. 86/609/EEC). The animals were kept for 55 days in multiple cages (five in each cage) equipped with feeders and an automatic watering system. The temperature and humidity of the rabbitry were continuously recorded with a digital thermograph positioned at the same level as the cages. Heating and forced ventilation systems allowed the building air temperature to be maintained within $18 \pm 4^{\circ} \mathrm{C}$ throughout the experiment. Relative humidity was $70 \pm 5 \%$. Growing rabbits were divided at random into three groups of 15 animals each, which were homogeneous in age ( $35 \pm 2$ days of age) and body weight $(1050.9 \pm 118.2 \mathrm{~g})$, were fed ad libitum and had free access to water until the end of the trial (90 days of age). Animals were fed a commercial diet assigned to three dietary treatments: control diet (CON) and a diet supplemented with $1 \mathrm{~kg} \mathrm{t}^{-1}$ of natural extract (low natural extract - LNE) or $2 \mathrm{~kg} \mathrm{t}^{-1}$ of natural extract (high natural extract - HNE). The experimental diets were prepared by adding the natural extract to the basal commercial mashed diet.
Rabbits were fed a weaning and fattening feed (dry matter (DM) was $88.5 \%$ of the total, which included crude proteins ( $16.5 \%$ of total), ether extract (3.2\% of total), neutral detergent fibre $(36.9 \%$ of total), acid detergent fibre $(20.6 \%$ of total), and digestible energy $11.71 \mathrm{MJ} \mathrm{kg}^{-1} \mathrm{DM}$, amongst other things) and the chemical composition was analysed in accordance with the methods of the Association of Analytical Chemists (AOAC, 2000).

The antioxidant supplement contains a water-soluble extract of Lippia citriodora leaves (Verbenaceae), prepared on an industrial scale by a standardized procedure that includes ultrasonic extraction with $60 \%$ aqueous ethyl alcohol followed by spray-drying with maltodextrins as an excipient.

The bioactive components of the feed supplement, according to a certificate of analysis provided by the manufacturer were verbascoside $(4.47 \pm 0.08)$, methyl gallate (1.91 \pm 0.09$)$, gallic acid $(1.75 \pm 0.07), 3.4$-dihydroxybenzoic acid $(0.45 \pm 0.04)$ and isoverbascoside $\left(0.43 \pm 0.04 \mathrm{~g} \mathrm{~kg}^{-1}\right)$.

The quantitative analysis of the phenolic compounds was performed by HPLC-UV-DAD (high-performance liquid chromatography, UV diode array detector) according to Piccinelli et al. (2004). To avoid oxidation in the complete feed, the supplement is micro-encapsulated within a protective matrix of hydrogenated vegetable lipids using spraycooling technology (Sintal Zootecnica, Isola Vicentina, Vicenza, Italy).

Body weights and feed intake were recorded on 35, 60 and 90 days to determine the average daily gain (ADG) and feed conversion index, calculated as kilograms of DM per kilograms of growth rate.

\subsection{Carcass traits}

Animals were slaughtered at the age of $90 \pm 2$ days in an experimental slaughterhouse. Rabbits were subjected to electrical stunning and sacrificed by bleeding, following the guidelines established by the European Community (1099/2099/EC 2009). The carcasses were prepared as reported by Blasco and Ouhayoun (1996) by removing the skin, the distal part of the limbs, genital organs, the bladder and the gastrointestinal tract. Body weight at slaughter and hot carcasses weight were recorded. The dressing percentage was calculated as kilograms of hot carcass weight per kilograms of body weight. The $\mathrm{pH}$ at $45 \mathrm{~min}\left(\mathrm{pH}_{45}\right)$ and at $24 \mathrm{~h}\left(\mathrm{pH}_{24} \mathrm{~h}\right)$ post-mortem were determined on Longissimus lumborum (LL) muscle using a Hanna Instruments $\mathrm{pH}$ meter (Woonsocket, USA) with a driven electrode. Colour measurements were performed according to the lab system $\left(\mathrm{L}^{*}\right.$ : lightness; $\mathrm{a}^{*}$ : redness; and $\mathrm{b}^{*}$ : yellowness) using a Minolta colorimeter CR-300 ${ }^{\circledR}$ (Minolta Camera Co., Osaka, Japan, illuminant D65 and $0^{\circ}$ observer) on a freshly cut LL slice, left to oxygenate at $4^{\circ} \mathrm{C}$ for $1 \mathrm{~h}$ and again $24 \mathrm{~h}$ after slaughter. Drip losses (at $48 \mathrm{~h}$ ) on LL meat samples were determined as described by Honikel (1998). 


\subsection{Chemical composition, oxidative stability and fatty acid profile of meat}

Samples from the LL of all animals were tested for the determination of DM, protein, fat and ash content according to the AOAC (2000) method. Lipid oxidation was determined by the TBARS method as described by $\mathrm{Du}$ et al. (2000) at 0,4 and 7 days of storage at $4{ }^{\circ} \mathrm{C}$. Briefly, $3 \mathrm{~g}$ of meat was weighed into a $50 \mathrm{~mL}$ test tube and homogenized with $15 \mathrm{~mL}$ of deionized distilled water using a Polytron homogenizer (type PT 10/35, Brinkmann Instruments, Inc., Westbury, NY, USA) for $10 \mathrm{~s}$ at highest speed. One millilitre of the meat homogenate was transferred to a disposable test tube $(3 \times 100 \mathrm{~mm})$, and butylated hydroxyanisole $(50 \mathrm{~mL}, 7.2 \%)$ and a solution of thiobarbituric acid and trichloroacetic acid (TBA-TCA) $(2 \mathrm{~mL})$ were added. The mixture was vortexed and then incubated in a boiling water bath for $15 \mathrm{~min}$ to develop colour. The sample was then cooled in cold water for $10 \mathrm{~min}$, vortexed again and centrifuged for $15 \mathrm{~min}$ at $2000 \mathrm{~g}$. The absorbance of the resulting supernatant solution was determined at $531 \mathrm{~nm}$ against a blank containing $1 \mathrm{~mL}$ of deionized distilled water and $2 \mathrm{~mL}$ of TBA-TCA solution. The amounts of TBARS were determined by comparing the standard curve of absorbance at $531 \mathrm{~nm}$ for series of malondialdehyde solutions analysed by the same method, and expressed as milligrams of malondialdehyde per kilogram of meat.

Alpha-tocopherol and retinol were determined in muscle using a procedure modified from Zaspel and Csallany (1983). Muscle was analysed by an HPLC system (Kontron Instruments, Milan, Italy) consisting of an autosampler (HPLC autosampler 360, Kontron Instruments, Milan, Italy) with a loop of $20 \mu \mathrm{L}$, a high-pressure pump and a C18 column $5 \mu \mathrm{m}, 250 \times 4.60 \mathrm{~mm}$ (Phenomenex, Torrance, CA, USA). The mobile phase consisted of acetonitrile and methanol $(75: 25 v / v)$, and a flow rate of $1 \mathrm{~mL} \mathrm{~min}^{-1}$ was used. The alpha-tocopherol and retinol were identified by using a fluorimeter detector and comparing the samples' retention time with the pure standards (97\%) purchased from Sigma Aldrich (St. Louis, USA). The quantification was carried out using the Geminyx system (version 1.91) by comparing the area sample peak with that of the reference standards curve.

The fatty acid composition of meat samples was determined after chloroform-methanol extraction (Folch et al., 1957), and fatty acids were determined as methyl esters (FAMEs) (Dal Bosco et al., 2004) using a gas chromatograph (ThermoQuest TRACE 2000, SACtm-5 column $300 \mathrm{~cm} \times 0.25 \mathrm{~mm}$, Supelco, USA). The fatty acid percentages were calculated with the Chrom-Card software (version 1.17).

\subsection{Sensory analysis}

The LL preparation for sensory analysis was performed after thawing the LL section for $24 \mathrm{~h}$ at $4{ }^{\circ} \mathrm{C}$ and preparing it in one piece in an uncovered stainless-steel dish in a conventional oven (REX, Italy) at $150^{\circ} \mathrm{C}$. A thermocouple (Pentronic AB, Gunnebobruk, Sweden) was inserted into the centre of each piece of meat to register the core temperature. The LL was removed from the oven at 75 to $80^{\circ} \mathrm{C}$ to allow for post-heating rise. After cooling the entire LL muscle was cut into $1.5 \mathrm{~cm}$ thick slices (Electrolux 50, 220-24, kW 0.2). The LL slices were warmed to $60^{\circ} \mathrm{C}$ before the evaluation.

A trained sensory panel, consisting of eight members, familiar with descriptive analysis procedures (EN ISO 13299, 2010), was chosen. All assessments were carried out in a sensory laboratory equipped according to ISO 8598 (1989) recommendations. The list of descriptors, definitions, and standards (Nollet and Toldra, 2011) is shown in Table 1. The sensory profile was assessed according to EN ISO 13299 (2010) and the panel evaluated the samples in triplicate. Three samples (CON, LNE, HNE) were evaluated in each session on the same day. In order to reset the sensory evaluation following a previous session, during training and sampling, panellists had access to unlimited water and unsalted crackers. Panellists were requested to evaluate the intensity of each attribute by assigning a score between 1 (absence of the sensation) and 9 (extremely intense).

\subsection{Statistical analysis}

The statistical analysis was performed using the SPSS statistical package (version 18.0, 2009, SPSS Inc., USA). Data on productive performance, slaughter parameters, meat values of $\mathrm{pH}$ and colour, meat chemical composition, fatty acid profile and contents in vitamins (retinol and alpha-tocopherol) of meat were processed with one-way analysis of variance (ANOVA), with the dietary treatment (CON, LNE, HNE) as the source of variation. TBARS data on meat were processed using a general linear model (GLM) for repeated measurements, with dietary treatment, time of storage and their interaction as fixed factors. The mean values were compared using Duncan's test. Sensory profile results were analysed using ANOVA, with dietary treatment, panellists, the replication of the panel and the statistical interaction of these considerations as main factors. The significance of means was tested with the Fischer's test. Relationships between sensory scores and fatty acids of LL were assessed by Pearson correlation coefficients. The averages were compared according to the Student Newman Keuls (SNK) test. Data are presented as means \pm standard error of mean; a value of $P<0.05$ was used to indicate statistical significance, and a trend was noted when $P<0.10$.

\section{Results and discussion}

\subsection{Productive performance}

The present study provides new in vivo information about the use of verbascoside in rabbit nutrition and its effect 
Table 1. Descriptors, definition and standards used in sensory analysis.

\begin{tabular}{|c|c|c|}
\hline Attribute & Definition & Standard \\
\hline \multicolumn{3}{|l|}{ Aroma } \\
\hline $\begin{array}{l}\text { 1. Rabbit aroma } \\
\text { (wild) }\end{array}$ & $\begin{array}{l}\text { Aromatics associated with cooked rabbit meat perceived } \\
\text { through the sense of smell }\end{array}$ & Cut of beef ${ }^{1}$ \\
\hline 2. Liver aroma & $\begin{array}{l}\text { Aromatics associated with cooked liver perceived through } \\
\text { the sense of smell }\end{array}$ & Rabbit liver cooked ${ }^{2}$ \\
\hline 3. Rancid & $\begin{array}{l}\text { Aromatics associated with rancid or oxidized fat perceived } \\
\text { through the sense of smell }\end{array}$ & Fat oxidized with air ${ }^{2}$ \\
\hline \multicolumn{3}{|l|}{ Tastes } \\
\hline 4. Sweet & $\begin{array}{l}\text { One of the four basic tastes caused by aqueous solutions of } \\
\text { various substances that are perceived on the tip of the tongue. }\end{array}$ & $\begin{array}{l}\text { Horse meat cooked on electric plate at } \\
\text { maximum power for } 3 \mathrm{~min}^{2}\end{array}$ \\
\hline 5. Salty & $\begin{array}{l}\text { One of the four basic tastes caused by aqueous solutions of } \\
\text { various substances that are perceived on the tip and along } \\
\text { the margins of the tongue. }\end{array}$ & $\begin{array}{l}\text { Rabbit meat boiled in salt water } \\
\left(15 \mathrm{~g} \mathrm{~L}^{-1} \mathrm{di} \mathrm{NaCl}\right) \text { for } 20 \mathrm{~min}^{2}\end{array}$ \\
\hline
\end{tabular}

\begin{tabular}{|c|c|c|}
\hline \multicolumn{3}{|l|}{ Flavour } \\
\hline $\begin{array}{l}\text { 6. Rabbit flavour } \\
\text { (wild) }\end{array}$ & $\begin{array}{l}\text { Characteristic aroma of cooked rabbit meat perceived through } \\
\text { taste and smell when swallowing. }\end{array}$ & Cut of beef ${ }^{1}$ \\
\hline 7. Liver flavour & $\begin{array}{l}\text { Characteristic aroma of cooked liver perceived through taste } \\
\text { and smell when swallowing. }\end{array}$ & Cooked rabbit liver ${ }^{2}$ \\
\hline 8. Rancid & $\begin{array}{l}\text { Characteristic aroma of oxidized fat perceived through taste and } \\
\text { smell when swallowing. }\end{array}$ & Fat oxidized with air ${ }^{2}$ \\
\hline \multicolumn{3}{|l|}{ Texture } \\
\hline 9. Tenderness & $\begin{array}{l}\text { Minimum force required to compress a substance } \\
\text { between the molars }\end{array}$ & $\begin{array}{l}\text { Rare roast beef (extremely tender) }{ }^{2} \\
\text { slice of veal cooked on electric plate } \\
\text { at maximum power for } 10 \text { min (extremely } \\
\text { tough) } 1\end{array}$ \\
\hline 10. Juiciness & The degree of juice released while chewing the meat & Rare roast beef ${ }^{2}$ \\
\hline 11. Stringiness & Production of a large quantity of saliva for swallowing & $\begin{array}{l}\text { Chicken breast boiled in unsalted water } \\
\text { for } 45 \mathrm{~min}^{2}\end{array}$ \\
\hline
\end{tabular}

${ }^{1}$ Corresponding to the minimum score $\left(1-\right.$ absence of the sensation); ${ }^{2}$ corresponding to the maximum score ( 9 - extremely intense sensation).

on meat quality. Rabbits remained healthy throughout the study. Health was based on the absence of clinical signs. No mortality occurred throughout the trial. Performance data of growing rabbits are reported in Table 2. No differences were observed among the three dietary groups except with regard to feed intake, for which results were higher $(P=$ 0.049 ) in both supplemented groups than in CON. This result also affected the whole period. The higher feed intake in the experimental-group rabbits did not produce any improvement in the final body weight and feed conversion rate of animals. These results are consistent with Chrenkova et al. (2013), who found no significant effect on final body weight in growing rabbits fed a dry extract of Siberian ginseng (Eleutherococcus senticosus). Conversely, Zhao et al. (2005) showed an improvement in appetite and productive performance in growing rabbits fed with certain traditional Chinese herbs. More recently, Dal Bosco et al. (2014a) found a lower $(P<0.001)$ feed intake inrabbits fed with natural bioactive compounds (fresh alfalfa). Supplementing the diet with spirulina or/and thyme, Gerencséret al. (2012) found no effect on the rabbits' weight gain, body weight, feed consumption, morbidity and mortality.

The present study was not focused on the growth performance of rabbits since a low number of replicates was used. Moreover, the experimental controlled rearing condition, which was characterized by lower stress levels than intensive rearing conditions, could have affected the final results. According to Gerencsér et al. (2012), in a favourable environment where the rabbits have a high health status, no further increase in production can be achieved.

\subsection{Carcass traits}

Table 3 summarizes results on carcass traits; data relating to body weights at slaughter, hot carcass weights and dressing percentage are similar in all groups. Recently Simitzis et 
Table 2. Effect of Lippia citriodora extract on productive performance in growing New Zealand white rabbits.

\begin{tabular}{|c|c|c|c|c|c|}
\hline & \multicolumn{3}{|c|}{$\operatorname{Diet}^{1}$} & & \\
\hline & $\mathrm{CON}$ & LNE & HNE & & \\
\hline Items & $n=15$ & $n=15$ & $n=15$ & s.e.m. & $P$ value \\
\hline \multicolumn{6}{|l|}{ Body weight (kg) } \\
\hline Weaning at 35 days & 1.04 & 1.02 & 1.03 & 17.62 & 0.13 \\
\hline At 60 days & 1.97 & 1.86 & 1.92 & 36.98 & 0.32 \\
\hline At 90 days & 3.26 & 3.16 & 3.26 & 47.61 & 0.65 \\
\hline \multicolumn{6}{|c|}{ Average daily gain $\left(\mathrm{g} \mathrm{d}^{-1}\right)$} \\
\hline 35-60 days & 38.11 & 33.63 & 35.44 & 1.53 & 0.83 \\
\hline 60-90 days & 43.42 & 44.87 & 46.14 & 1.52 & 0.79 \\
\hline Whole trial 35-90 days & 40.96 & 39.66 & 41.18 & 0.81 & 0.52 \\
\hline \multicolumn{6}{|l|}{ Feed intake $\left(\mathrm{g} \mathrm{d}^{-1}\right)$} \\
\hline 35-60 days & 67.17 & 74.17 & 75.67 & 2.62 & 0.34 \\
\hline 60-90 days & $124.00^{3}$ & $135.00^{4}$ & $135.30^{4}$ & 2.91 & 0.05 \\
\hline Whole trial 35-90 days & 86.11 & 94.44 & 95.56 & 3.13 & 0.08 \\
\hline \multicolumn{6}{|l|}{ Feed conversion index ${ }^{2}$} \\
\hline 35-60 days & 1.76 & 2.20 & 2.13 & 0.31 & 0.28 \\
\hline 60-90 days & 2.85 & 3.01 & 2.93 & 0.62 & 0.15 \\
\hline Whole trial 35-90 days & 2.10 & 2.38 & 2.32 & 0.44 & 0.23 \\
\hline
\end{tabular}

${ }^{1}$ Diet: control group (CON); low natural extract (LNE); high natural extract (HNE). ${ }^{2}$ Calculated as kg of DM per kg growth rate. ${ }^{3,4}$ Values within a row with different superscripts differ significantly at $P<0.05$. s.e.m.: standard error of means.

al. (2014) in a study on dietary supplementation of hesperidin found similar body weight at slaughter ( 80 days of age) and carcass weights in Hyla hybrid rabbits. The $\mathrm{pH}$ value was only influenced by experimental treatment $(P=0.036)$ 45 min post-mortem showing lower $(-7.7 \%)$ values in HNE group compared to the CON group. However, at $24 \mathrm{~h}$, in all studied groups, $\mathrm{pH}$ values were in agreement with the literature (Castellini et al., 1998) and no statistical differences among groups are reported.

Lightness $\left(\mathrm{L}^{*}\right)$, detected $24 \mathrm{~h}$ post-mortem, highlighted a significant effect $(P=0.014)$ of dietary treatment with a lower value in the two experimental groups compared with the CON group. No statistical difference was found for $\mathrm{a}^{*}$ and $b^{*}$ indices among groups during two monitored samplings.

Generally the increase in lightness can be due, in part, to some modifications occurring in the muscular fibres during storage, such as the reduction in the cellular membrane integrity, also caused by the shrinkage of myofibrils. This, in turn, can cause a passage of liquids from the cells to extracellular spaces, which leads to an increase in light reflection.

From a commercial point of view, an increase in the lightness in rabbit meat during storage could be considered as a positive factors, since consumers associate a light colour in

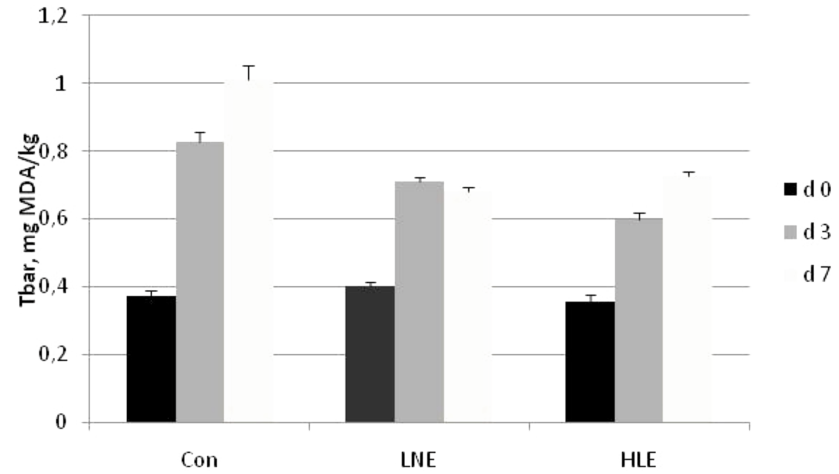

Figure 1. Effect of Lippia citriodora extract on thiobarbituric acid reactive substances (TBARSs) during storage at $4{ }^{\circ} \mathrm{C}$ of the Longissimus lumborum muscle. Groups: control group $(\mathrm{CON})$; low natural extract (LNE); high natural extract (HNE). Time effect: $P<0.001$; diet effect: $P=0.063$.

"white meats" with better dietetic and nutritional characteristics (Lo Fiego et al., 2004).

\subsection{Chemical composition and oxidative stability of meat}

Chemical composition was unaffected by dietary treatment (Table 4) according to Dal Bosco et al. (2004), who reported 
Table 3. Effect of Lippia citriodora extract on slaughter parameters and carcass traits in growing New Zealand white rabbits.

\begin{tabular}{|c|c|c|c|c|c|}
\hline & \multicolumn{3}{|c|}{ Diet $^{1}$} & & \\
\hline & $\mathrm{CON}$ & LNE & $\mathrm{HNE}$ & & \\
\hline Items & $n=15$ & $n=15$ & $n=15$ & s.e.m. & $P$ value \\
\hline \multicolumn{6}{|l|}{ Slaughter parameters } \\
\hline Body weight $(\mathrm{kg})$ & 3.26 & 3.16 & 3.26 & 47.61 & 0.65 \\
\hline Hot carcass weight $(\mathrm{kg})$ & 1.97 & 1.94 & 2.00 & 30.74 & 0.32 \\
\hline Internal organ weight ${ }^{2}(\mathrm{~g})$ & 173.07 & 171.47 & 171.20 & 4.58 & 0.98 \\
\hline Skin weight $(\mathrm{g})$ & 590.93 & 580.53 & 616.67 & 9.90 & 0.79 \\
\hline Drip loss after $48 \mathrm{~h}(\%)$ & 8.97 & 9.08 & 11.79 & 0.92 & 0.30 \\
\hline Dressing percentage (\%) & 60.38 & 61.41 & 61.36 & 1.31 & 0.08 \\
\hline \multicolumn{6}{|l|}{ Carcass traits } \\
\hline \multicolumn{6}{|l|}{$\mathrm{pH}$} \\
\hline At $0 \mathrm{~h}$ & $6.34^{3}$ & $6.20^{3}$ & $5.85^{4}$ & 0.05 & 0.04 \\
\hline At $24 \mathrm{~h}$ & 5.71 & 5.68 & 5.66 & 0.02 & 0.52 \\
\hline \multicolumn{6}{|l|}{ Colour $_{0}$} \\
\hline $\mathrm{L}^{*}$ & 46.32 & 46.27 & 46.03 & 0.50 & 0.89 \\
\hline$a^{*}$ & 1.43 & 1.34 & 1.32 & 0.18 & 0.71 \\
\hline$b^{*}$ & 7.28 & 6.98 & 6.87 & 0.12 & 0.69 \\
\hline \multicolumn{6}{|l|}{ Colour $_{24}$} \\
\hline $\mathrm{L}^{*}$ & $55.00^{3}$ & $52.23^{4}$ & $52.25^{4}$ & 0.46 & 0.01 \\
\hline$a^{*}$ & 1.11 & 0.99 & 1.21 & 0.16 & 0.11 \\
\hline$b^{*}$ & 8.37 & 7.33 & 7.80 & 0.18 & 0.05 \\
\hline
\end{tabular}

Table 4. Effect of Lippia citriodora extract on chemical composition and oxidative stability of meat in New Zealand white rabbits.

\begin{tabular}{lrrrrr}
\hline & \multicolumn{5}{c}{ Diet $^{1}$} \\
\cline { 2 - 5 } & CON & LNE & HNE & \\
\hline Items & $n=15$ & $n=15$ & $n=15$ & s.e.m. & $P$ value \\
\hline Chemical composition (\% of raw meat) & & & & & \\
\hline Moisture & 72.91 & 72.92 & 73.00 & 0.76 & 0.98 \\
Crude protein & 24.22 & 24.11 & 23.99 & 0.51 & 0.93 \\
Ether extract & 1.48 & 1.34 & 1.32 & 0.38 & 0.74 \\
Ash & 1.84 & 2.09 & 1.82 & 0.11 & 0.64 \\
\hline Oxidative stability & & & & & \\
\hline Alfa-tocopherol (mg 100 g ${ }^{-1}$ ) & 0.14 & 0.17 & 0.24 & 0.22 & 0.07 \\
Retinol (mg 100 g & & & & & \\
\hline
\end{tabular}

${ }^{1}$ Diet: control group (CON); low natural extract (LNE); high natural extract (HNE). s.e.m.: standard error of means.

no effect on the meat composition of rabbits fed with antioxidants. The influences of dietary supplementation with natural extract on lipid oxidation in the LL muscle of growing rabbits is presented graphically in Fig. 1. The values of TBARS are similar to those found by Corino et al. (2007) and Ebeid et al. (2013) during storage time.
Generally, lipid oxidation increased $(P<0.001)$ with storage time in all groups. Dietary treatment with natural antioxidants tended to improve $(P=0.063)$ oxidative stability. On average, the TBARS values were lower in the HNE group than in the CON and LNE groups that showed an intermediate level consistent with the level of dietary integration. 
Table 5. Effect of Lippia citriodora extract on fatty acid composition (\% of total fatty acids) of meat in New Zealand white rabbits.

\begin{tabular}{|c|c|c|c|c|c|}
\hline & \multicolumn{3}{|c|}{ Diet $^{1}$} & & \\
\hline & $\mathrm{CON}$ & LNE & HNE & & \\
\hline Items & $n=15$ & $n=15$ & $n=15$ & s.e.m. & $P$ value \\
\hline \multicolumn{6}{|c|}{ Individual fatty acids } \\
\hline C14:0 & 2.25 & 2.05 & 2.22 & 0.08 & 0.60 \\
\hline C16:0 & $34.44^{11}$ & 32.92 & $30.28^{12}$ & 0.53 & $<0.01$ \\
\hline C18:0 & $10.78^{11}$ & $9.26^{12}$ & $8.81^{12}$ & 0.22 & $<0.01$ \\
\hline C20:0 & 0.31 & 0.30 & 0.34 & 0.02 & 0.44 \\
\hline $\mathrm{C} 22: 0$ & 0.72 & 0.68 & 0.72 & 0.02 & 0.64 \\
\hline Other $\mathrm{SFA}^{2}$ & $1.25^{11}$ & $0.62^{12}$ & $0.63^{12}$ & 0.06 & $<0.01$ \\
\hline C14:1n-6 & 0.32 & 0.31 & 0.32 & 0.03 & 0.99 \\
\hline C16:1n-7 & 3.84 & 4.51 & 4.65 & 0.17 & 0.11 \\
\hline C18:1n-9 & 23.16 & 23.32 & 24.29 & 0.32 & 0.30 \\
\hline C20:1n-9 & 0.15 & 0.34 & 0.23 & 0.06 & 0.36 \\
\hline Other MUFA ${ }^{3}$ & 0.58 & 0.62 & 0.62 & 0.04 & 0.87 \\
\hline C18:2n-6 & $17.52^{11}$ & $19.53^{12}$ & $20.39^{12}$ & 0.45 & $<0.05$ \\
\hline $\mathrm{C} 18: 3 n-3$ & $2.05^{11}$ & $2.10^{11,12}$ & $2.39^{12}$ & 0.11 & $<0.05$ \\
\hline $\mathrm{C} 20: 3 \mathrm{n}-3$ & 0.14 & 0.21 & 0.19 & 0.02 & 0.13 \\
\hline$C 20: 3 n-6$ & 0.14 & 0.37 & 0.23 & 0.06 & 0.25 \\
\hline$C 20: 4 n-6$ & $0.91^{11}$ & $0.98^{11}$ & $1.65^{12}$ & 0.12 & $<0.05$ \\
\hline$C 20: 5 n-3$ & $0.18^{11}$ & $0.32^{12}$ & $0.31^{12}$ & 0.03 & $<0.05$ \\
\hline$C 21: 5 n-3$ & 0.39 & 0.43 & 0.44 & 0.02 & 0.67 \\
\hline$C 22: 5 n-3$ & $0.15^{11}$ & $0.21^{12}$ & $0.19^{12}$ & 0.01 & $<0.05$ \\
\hline$C 22: 6 n-3$ & $0.47^{11}$ & $0.62^{12}$ & $0.88^{13}$ & 0.08 & $<0.01$ \\
\hline Other PUFA ${ }^{4}$ & 0.27 & 0.29 & 0.25 & 0.02 & 0.59 \\
\hline \multicolumn{6}{|c|}{ Sums of fatty acids } \\
\hline Total SFA ${ }^{5}$ & $49.75^{11}$ & $45.83^{12}$ & $43.00^{12}$ & 0.65 & $<0.01$ \\
\hline Total MUFA $^{6}$ & 28.05 & 29.11 & 30.12 & 0.41 & 0.11 \\
\hline Total PUFA ${ }^{7}$ & $22.48^{11}$ & $24.91^{12}$ & $26.89^{12}$ & 0.62 & 0.01 \\
\hline$n-3^{8}$ & $3.38^{11}$ & 3.89 & $4.38^{12}$ & 0.16 & $<0.05$ \\
\hline$n-6^{9}$ & $18.57^{11}$ & $20.88^{11,12}$ & $22.27^{12}$ & 0.52 & $<0.01$ \\
\hline $\begin{array}{l}\text { Ratio } \\
n-6 / n-3^{10}\end{array}$ & 5.76 & 5.66 & 5.35 & 0.23 & 0.74 \\
\hline $\begin{array}{l}{ }^{1} \text { Diet: control group } \\
\text { fatty acid. }{ }^{3} \text { Monoun } \\
5 \text { Total SFA (C14:0+ } \\
6 \text { Total MUFA (C14: } \\
{ }^{7} \text { Total PUFA (C18:2 } \\
\text { C22:5n } 3 \text { + C22:6n } 3 \\
{ }^{8} \text { Sum of PUFA of n- } \\
\text { C21:5n3 + C22:5n } 3 \\
9 \text { Sum of PUFA of n- } \\
\left(\sum \text { n-6 / } \sum \text { n-3). }\right. \\
P<0.05 \text {. s.e.m.: stan } \\
P<1\end{array}$ & $\begin{array}{l}\mathrm{C} 18: 0+\mathrm{C} 20: \\
6+\mathrm{C} 16: 1 \mathrm{n} 7 \\
6+\mathrm{C} 18: 3 \mathrm{n} 3 \\
\text { other PUFA). } \\
\text { series (C18:3 } \\
\text { C22:6n3). } \\
\text { series (C18:2 } \\
13 \text { Values wit }\end{array}$ & $\begin{array}{l}\text { ural extract (LNE } \\
\text { cid. }{ }^{4} \text { Polyunsatu } \\
+\mathrm{C} 22: 0+\text { other } \\
+\mathrm{C} 18: 1 \mathrm{n} 9+\mathrm{C} 20 \\
\mathrm{C} 20: 3 \mathrm{n} 3+\mathrm{C} 20 \text { : } \\
3+\mathrm{C} 20: 3 \mathrm{n} 3+\mathrm{C} \\
6+\mathrm{C} 20: 3 \mathrm{n} 6+\mathrm{C} \\
\text { lin a row with dif } \\
\text { eans }\end{array}$ & $\begin{array}{l}\text {; high natural } \\
\text { ated fatty acid } \\
\text { FA). } \\
\text { 1n9 + other M } \\
\text { n6 + C20:4n6 } \\
\text { 20:5n3+ } \\
20: 4 n 6) .{ }^{10} \mathrm{R} \\
\text { erent superscr }\end{array}$ & $\begin{array}{l}\text { JFA). } \\
+ \text { C20:5n3 }\end{array}$ & C21:5n3+ \\
\hline
\end{tabular}

Several studies have been conducted in vivo in order to test natural compounds able to improve lipid stability in rabbit meat. It has been demonstrated that dietary supplementation with both synthetic and natural antioxidants such as vitamin E (Corino et al., 1999, 2007; Ebeid et al., 2013) and natural extracts (Dal Bosco et al., 2014b) may improve meat shelf life.

A clear antioxidant dose response effect has not always been observed. For instance, Smet et al. (2008) found higher TBARS values with increasing doses of green tea extracts (100 and $200 \mathrm{mg} \mathrm{kg}^{-1}$ ) in broiler meat. Conversely dietary supplementation with polyphenols is recognized to increase oxidative stability in post-mortem skeletal poultry muscle (Bou et al., 2009).
However, caution is required when applying the results of the different antioxidant treatments because commercial extracts used may contain different levels of active compounds and different adsorption pathways; moreover, differences can be expected between species since each one is characterized by own assimilation and utilization of intake. No other study reported the effects of dietary supplementation with verbascoside on meat oxidative stability in rabbit.

In the present study the content of alpha-tocopherol in the LL showed a trend effect of the treatment $(P=0.07)$ compared to the CON group. Thus, consistent with the results of TBAR and alpha-tocopherol content in muscle, an inverse relationship with borderline significance $(P=0.057)$ was found. Control values of alpha-tocopherol are in agreement with those found by Corino et al. (1999), Oriani et al. (2001) and slightly higher than found Dal Bosco et al. (2014a). No significant differences in the retinol meat content of the three groups were found. These data suggest that the dietary plant extract slowed the lipid oxidation in fresh muscle through an increase in alpha-tocopherol content in meat, as recently found by Rossi et al. (2013) in pigs and by Vizzarri et al. (2014) in hares.

\subsection{Fatty acid composition of meat}

Table 5 reports the total fatty acid composition of the LL muscle. It shows that saturated fatty acids (SFAs) were significantly affected $(P=0.001)$ by dietary treatment, with a decrease in both treated groups compared to the CON group: $7.9 \%$ in the LNE group and $13.6 \%$ in the HNE group. Polyunsaturated fatty acids (PUFAs) showed a significant increase $(P=0.010)$ in the two experimental groups compared with the CON group (10.8 and $19.6 \%$ respectively in LNE and HNE). This increase is due to the significant increase in linoleic acid (11.5\% in LVB and $16.4 \%$ in HNE; $P=0.019)$, arachidonic acid $(81.3 \%$ in HNE; $P=$ $0.015)$, eicosapentaenoic acid (77.8\% in LNE and $72.2 \%$ in HNE; $P=0.021)$, docosapentaenoic acid $(40.0 \%$ in LNE and $28.6 \%$ in HNE; $P=0.035$ ) and docosahexaenoic acid (31.9\% in LNE and $87.2 \%$ in HNE; $P=0.001$ ). Total fatty acids $\mathrm{n}-3$ and $\mathrm{n}-6$ in the HNE group had higher values by $29.6 \%(P=0.035)$ and $19.9 \%(P=0.007)$ than CON.

Our results underline that dietary supplement has positively influenced the acid composition of raw rabbit meat, leading to a reduction in SFA and an increase in PUFA. These results are in agreement with Meineri et al. (2010), who founds a dose-dependent increase in C18:2 (n-6) and C18:3 (n-3) in rabbits whose feed was supplemented with seeds of Salvia hispanica. Even Jung et al. (2010) found a reduction in SFA and monounsaturated fatty acid (MUFA) and an increase in PUFA content in broiler breast after feed was supplemented with a mixture of polyphenols (gallic acid) and linoleic acid. The authors reported that the increased level of PUFAs could reduce the synthesis of MUFA by inhibiting the activity of D9-desaturase, a key enzyme that converts 


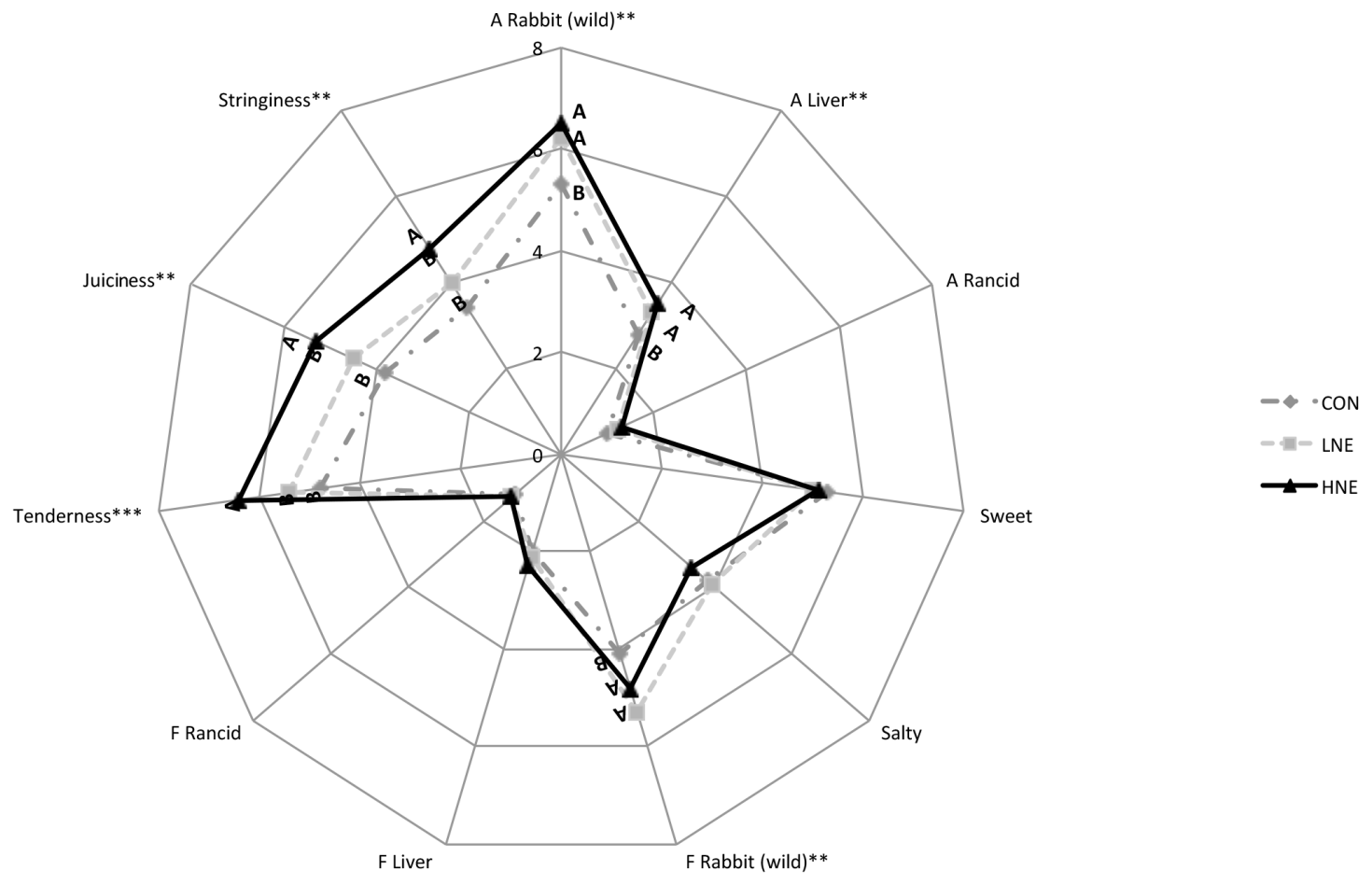

Figure 2. Sensory evaluation of Longissimus lumborum muscle in relation to dietary treatments. Groups: control group (CON); low natural extract (LNE); high natural extract (HNE). Significance: ${ }^{* *} P<0.01$; ${ }^{* * *} P<0.001$; A: aroma; F: flavour.

SFA into MUFA, and, therefore, the supplementation with antioxidants is an early strategy to reduce the concentrations of SFA and increase PUFA in the chicken meat.

\subsection{Sensory evaluation}

The least squares means of the different attributes for the samples of rabbit meat are reported in the spider plot (Fig. 2). Analysis of variance of the sensory characteristics of each attribute showed a dietary treatment effect for the rabbit (aroma and flavour), liver flavour, tenderness and juiciness descriptors. The panellist effect was significant $(P<0.01)$ for all descriptors; this statement is very common in sensory evaluation because of a different use of scores and a disagreement within the assessment of sample (Lea et al., 1997). No effect for replicates and no interaction between panellists $\times$ replicates and samples $\times$ replicates were found (data not shown). These results underline the excellent reproducibility of scores given by the panellists and excellent homogeneity of samples during repetitions. Aroma or flavour attributes of LNE and HNE rabbit meat showed the same intensity, which led to significantly different results from the CON group.

The supplementation with Lippia citriodora extract at the highest dosage improved the tenderness and juiciness of meat, highlighting a better consistency than in the $\mathrm{CON}$ and LNE groups. In the present research, the HNE group showed fatty acid n-3 series content which was significantly higher than in the CON and LNE groups, due to a significant increase in C18:3 (n-3) fatty acid. This result needs to be confirmed by further study. Dal Bosco et al. (2004) showed that rabbits fed with flaxseed and tocopherol acetate had higher values $(P<0.05)$ of final tenderness (fresh muscle) and overall acceptability (stored muscle) than rabbits from the CON group. Similar results were found by Kowalska and Bielański (2009), who found tenderness and juiciness significantly improved in rabbits whose diet was supplemented with $3 \%$ fish oil.

The differences related to the juiciness are not easy to explain because no difference in chemical parameters of LL muscle were found. We assumed that the result could be due to the increase in the fatty acid n-3 series, as confirmed by the Pearson correlation coefficient found between n-3 content and texture attributes (tenderness $r=0.634$ and juiciness $r=0.583$ ). A negative correlation was found between SFA and the same texture attribute $(r=-0.582$ tenderness and juiciness $r=-0.543$ ).

Sensory analysis results are consistent with a study that emphasizes the importance for consumers of meat juiciness and tenderness (Talukder, 2013). Consumers consider rabbit meat for its attractive sensory properties, represented by tenderness, leanness and delicate flavour (game-like taste) (Gašperlin et al., 2006). 
In the present study no tests on consumers has been done and therefore no unique conclusion could be formulated on the acceptability. However, it should be noted that the sensory properties of rabbit meat do not depend only on the breed, type of muscle (Szkucik and Pyz-Łukasik, 2008) and the age of the animals (Corino et al., 2002) but also on dietary treatment.

\section{Conclusion}

In conclusion the results suggest that the supplementation with Lippia citriodora extract, under the experimental conditions, showed a trend towards a reduction in oxidation of TBARS in treated groups, as shown by the trend of increasing alpha-tocopherol content. A significant reduction in SFA and an increase in PUFA was found. No detrimental effects on physical and chemical parameters were observed.

Therefore, the natural extract enhanced aroma, flavour, tenderness and juiciness of rabbit meat. This study shows that the natural Lippia citriodora extract has the potential to produce rabbit meat beneficial to human health.

Acknowledgements. Supported by the Ministry for Universities and Scientific and Technological Research, Italy (PRIN 2008).

Edited by: S. Maak

Reviewed by: P. Massanyi and one anonymous referee

\section{References}

Afanasev, B.: Superoxide and nitric oxide in pathological conditions associated with iron overload. The effects of antioxidants and chelators, Curr. Med. Chem., 12, 2731-2739, 2005.

Aleo, E., Ricci, R., Passi, S., and Cataudella, S.: A novel cyt $\mathrm{C}-\mathrm{H}_{2} \mathrm{O}_{2}$ - chemiluminescence assay for measuring the reducing/antioxidant capacity of a wide range of hydrophilic and lipophilic antioxidants and biological samples, Prog. Nutr., 3, 154-182, 2005.

Association of Official Analytical Chemists: Official methods of analysis, 2 Vol. 18th Edn., AOAC, Arlington, VA, USA, 2000.

Blasco, A. and Ouhayoun, J.: Harmonization of criteria and terminology in rabbit meat research, Revised proposal, World Rabbit. Sci., 4, 93-99, 1996.

Bou, R., Codony, R., Tres, A., Decker, E. R., and Guardiola, F.: Dietary strategies to improve nutritional value, oxidative stability, and sensory properties of poultry products, Crit. Rev. Food Sci., 49, 800-822, 2009.

Casamassima, D., Palazzo, M., D’Alessandro, A. G., Colella, G. E., Vizzarri, F., and Corino, C.: The effects of lemon verbena (Lippia citriodora) verbascoside on productive performance, plasma oxidative status, and some blood metabolites in suckling lambs, J. Anim. Feed Sci., 22, 204-212, 2013.

Castellini, C., Dal Bosco, A., Bernardini, M., and Cyril, H. V.: Effect of dietary vitamin $\mathrm{E}$ on the oxidative stability of raw and cooked rabbit meat, Meat Sci., 50, 153-161, 1998.
Chrenková, M., Chrastinová, L., Lauková, A., Poláčiková, M., Formelová, Z., Plachá, I., Pogány-Simonová, M., Szabóová, R., Ondruška, L., Parkányi, V., Rafay, J., Jurčík, R., and Strompfová, V.: The effect of dietary supplementation of herbal extracts on growth performance and health status of rabbits, J. Microbiol. Biotechn. Food Sci., 2, 2067-2073, 2013.

Corino, C., Lo Fiego, D. P., Macchioni, P., Pastorelli, G., Di Giancamillo, A., Domeneghini, C., and Rossi, R.: Influence of dietary conjugated linoleic acids and vitamin $\mathrm{E}$ on meat quality and adipose tissue in rabbits, Meat Sci., 76, 19-28, 2007.

Corino, C., Mourot, J., Magni, S., Pastorelli, G., and Rosi, F.: Influence of dietary conjugated linoleic acid on growth, meat quality, lipogenesis, plasma leptin and physiological variables of lipid metabolism in rabbits, J. Anim. Sci., 80, 1020-1028, 2002.

Corino, C., Pastorelli, G., Pantaleo, L., Oriani, G., and Salvatori, G.: Improvement of color and lipid stability of rabbit meat by dietary supplementation with vitamin E, Meat Sci., 52, 285-289, 1999.

Dal Bosco, A., Castellini, C., Bianchi, L., and Mugnai, C.: Effect of dietary $\alpha$-linolenic acid and vitamin $\mathrm{E}$ on the fatty acid composition, storage stability and sensory traits of rabbit meat, Meat Sci., 66, 407-413, 2004.

Dal Bosco, A., Mugnai, C., Roscini, V., Mattioli, S., Ruggeri, S., and Castellini, C.: Effect of dietary alfalfa on the fatty acid composition and indexes of lipid metabolism of rabbit meat, Meat Sci., 96, 606-609, 2014a.

Dal Bosco, A., Gerencsér, Z. S., Szendrõ, Z. S., Mugnai, C., Cullere, M., Kovàcs, M., Ruggeri, S., Mattioli, S., Castellini, C., and Dalle Zotte, A.: Effect of dietary supplementation of Spirulina (Arthrospira platensis) and Thyme (Thymus vulgaris) on rabbit meat appearance, oxidative stability and fatty acid profile during retail display, Meat Sci., 96, 114-119, 2014b.

Dalle Zotte, A.: Rabbit farming for meat purposes, Animal Frontiers, 4, 62-67, 2014.

Dalle Zotte, A. and Szendro, Z.: The role of rabbit meat as functional food, Meat Sci., 88, 319-331, 2011.

Du, M., Ahn, D. U., Nam, K. C., and Sell, J. L.: Influence of dietary conjugated linoleic acid on volatile profiles, color and lipid oxidation of irradiated raw chicken, Meat Sci., 56, 387-395, 2000.

Ebeid, T. A., Zeweil, H. S., Basyony, M. M., Dosoky, W. M., and Badry, H.: Fortification of rabbit diets with vitamin E or selenium affects growth performance, lipid peroxidation, oxidative status and immune response in growing rabbits, Livestock Sci., 155, 323-331, 2013.

European Communities: Council Directive 86/609/EEC of 24 November 1986 on the approximation of laws, regulations and administrative provisions of the Member States regarding the protection of animals used for experimental and other scientific purposes, available at: http://eur-lex.europa.eu/LexUriServ/ LexUriServ.do?uri=CELEX:31986L0609:EN:HTML (last access: June 2015), 1986.

European Communities: Council Regulation (EC) 1099/2009 on the Protection of Animals at the Time of Killing, available at: http://eur-lex.europa.eu/legal-content/IT/TXT/HTML/ ?uri=CELEX:32009R1099\&rid=2 (last access: June 2015), 2009.

Folch, J., Lees, M., and Stanley, G. H. S.: A simple method for the isolation and purification of total lipids from animal tissues, J. Biol. Chem., 226, 497-509, 1957. 
Gašperlin, L., Polak, T., Rajar, A., Skvarèa, M., and Zlender, B.: Effect of genotype, age at slaughter and sex on chemical composition and sensory profile of rabbit meat, World Rabbit Sci., 14, 157-166, 2006.

Gerencsér, Zs., Szendrő, Zs., Matics, Zs., Radnai, I., Kovács, M., Nagy, I., Dal Bosco, A., and Dalle Zotte, A.: Dietary supplementation of Spirulina (Arthrospira platensis) and Thyme (Thymus vulgaris L.) - Part 1: effect on productive performance of growing rabbits, in: 10th World Rabbit Congress, Sharm El-Sheikh, Egypt, 3-6 September 2012, 657-661, 2012.

Hernández, P. and Gondret, F.: Rabbit Meat Quality, in: Recent Advances in Rabbit Sciences, edited by: Maertens, L. and Coudert, P., ILVO, Merelbeke, Belgium, 269-290, 2006.

Honikel, K. O.: Reference methods for the assessment of physical characteristics of meat, Meat Sci., 49, 447-457, 1998.

ISO 8598: Sensory analysis: General guidance for design of test rooms, International Organization for Standardization, Geneva, Switzerland, 1989.

ISO International Organization for Standardization: Sensory analysis- Methodology-General guidance to establish a sensory profile, ISO 13299:2010, Geneva, Switzerland, 2010.

Jung, S., Choe, J. H., Kim, B., Yun, H., Kruk, Z. A., and Jo, C.: Effect of dietary mixture of gallic acid and linoleic acid on antioxidative potential and quality of breast meat from broilers, Meat Sci., 86, 520-526, 2010.

Karre, L., Lopez, K., and Getty, K. J. K.: Natural antioxidants in meat and poultry products, Meat Sci., 94, 220-227, 2013.

Kowalska, D. and Bielański, D.: Meat quality of rabbits fed a diet supplemented with fish oil and antioxidant, Anim. Sci. Pap. Rep., 27, 139-148, 2009.

Laudadio, V., Ceci, E. W., Lastella, N. M., and Tufarelli, V.: Dietary high-pliphenols extra-virgin olive oil is effective in reducing cholesterol content in eggs, Lipids Health Dis., 14, 7 pp., doi:10.1186/s12944-015-0001-x, 0015.

Lea, P., Tormod, N., and Morit, R.: Analysis of variance for sensory data, John Wiley and Sons Ltd., England, 1997.

Lo Fiego, D. P., Santoro, P., Macchioni, P., Mazzoni, D., Piattoni, F., Tassone, F., and Leonibus, E.: The effect of dietary supplementation of vitamins $\mathrm{C}$ and $\mathrm{E}$ on the a-tocopherol content of muscles, liver and kidney, on the stability of lipids, and on certain meat quality parameters of the longissimus dorsi of rabbits, Meat Sci., 67, 319-327, 2004.

Lukefahr, S. D., Nwosu, C. V., and Rao, D. R.: Cholesterol level of rabbit meat and trait relationships among growth, carcass and lean yield performances, J. Anim. Sci., 67, 2009-2017, 1989.

Meineri, G., Cornale, P., Tassone, S., and Peiretti, P. G.: Effects of Chia (Salvia hispanica L.) seed supplementation on rabbit meat quality, oxidative stability and sensory traits, Ital. J. Anim. Sci., 9, 45-49, 2010.

Nollet, L. M. L. and Toldra, F.: Sensory analysis of foods of animal origin, edited by: Toldra. F., CRC Press, Boca Raton, Florida, USA, 2011.

Olmedilla-Alonso, B., Granado-Lorencio, F., Herrero-Barbudo, C., and Blanco-Navarro, I.: Nutritional approach for designing meatbased functional food products with nuts, Crit. Rev. Food Sci., 46, 537-542, 2006.
Oriani, G., Corino, C., Pastorelli, G., Pantaleo, L., Ritieni, A., and Salvatori, G.: Oxidative status of plasma and muscle in rabbits supplemented with dietary vitamin E, J. Nutr. Biochem., 12, 138-143, 2001.

Pascual, M. E., Slowing, K., Carretero, E., Sanchez Mata, D., and Villar, A.: Lippia: traditional uses, chemistry and pharmacology: A review, J. Ethnopharmacol., 76, 201-214, 2001.

Pereira, D. M., Valentão, P., Pereira, J. A., and Andrade, P. B.: Phenolics: from chemistry to biology, Molecules, 14, 2202-2211, 2009.

Piccinelli, A. L., De Simone, F., Passi, S., and Rastrelli, L.: Phenolic constituents and antioxidant activity of Wendita calysina leaves (burrito), a folk Paraguayan tea, J. Agr. Food Chem., 52, 58635868, 2004.

Rossi, R., Pastorelli, G., Cannata, S., Tavaniello, S., Maiorano, G., and Corino, C.: Effect of long-term dietary supplementation with plant extract on carcass characteristics meat quality and oxidative stability in pork, Meat Sci., 95, 542-548, 2013.

Simitzis, P. E., Babaliaris, C., Charismiadou, M. A., Papadomichelakis, G., Goliomytis, M., Symeon, G. K., and Deligeorgis, S. G.: Effect of hesperidin dietary supplementation on growth performance, carcass traits and meat quality of rabbits, World Rabbit Sci., 22, 113-121, 2014.

Smet, K., Raes, K., Huyghebaert, G., Haak, L., Arnouts, S., and De Smet, S.: Lipid and protein oxidation of broiler meat as influenced by dietary natural antioxidant supplementation, Poultry Sci., 87, 1682-1688, 2008.

SPSS/PC Statistics: SPSS/PC Statistics 18.0, SPSS Inc., Chicago, IL, USA, 2009.

Szkucik, K. and Pyz-Łukasik, R.: Variability of sensory features of rabbit meat in relation to breed and part of carcass, Med. Weter., 64, 1308-1310, 2008.

Talukder, S.: Effect of dietary fiber on properties and acceptance of meat products: A review, Crit. Rev. Food Sci., 55, 1005-1011, doi:10.1080/10408398.2012.682230, 2013.

Vizzarri, F., Nardoia, M., and Palazzo, M.: Effect of dietary Lippia citriodora extract on productive performance and meat quality parameters in hares (Lepus europaeus Pall.), Arch. Tierz., 57, 17, doi:10.7482/0003-9438-57-020, 2014.

Wang, P., Kang, J., Zheng, R., Yang, Z., Lu, J., Gao, J., and Jia, Z.: Scavenging effects of phenylpropanoid glycosides from Pedicularis on superoxide anion and hydroxyl radical by spin trapping method, Biochem. Pharmacol., 51, 687-691, 1996.

Zaspel, B. J. and Csallany, A. S.: Determination of a-tocopherol in tissues and plasma by high-performance liquid chromatography, Anal. Biochem., 130, 146-150, 1983.

Zhao, H. Q., Xu, H. J., Du, W. B., Li, L., Zhang, D. F.: Research and applications of Chinese herbal additives, Chinese J. Rabbit Farm., 1, 31-33, 2005. 